Article

\title{
Eliminating Overload Trucking via a Modal Shift to Achieve Intercity Freight Sustainability: A System Dynamics Approach
}

\author{
Pei Liu ${ }^{1,2}$, Dong Mu ${ }^{1, *}$ and Daqing Gong ${ }^{3}$ \\ 1 Department of Logistics Management, School of Economics and Management, Beijing Jiaotong University, \\ Beijing 100044, China; liupei@sdu.edu.cn \\ 2 Department of Logistics Management, School of Business, Shandong University at Weihai, \\ Weihai 264209, China \\ 3 Department of Management Science and Engineering, School of Economics and Management, \\ Tsinghua University, Beijing 100084, China; gongdq@sem.tsinghua.edu.cn \\ * Correspondence: 11113156@bjtu.edu.cn; Tel.: +86-10-5168-7167
}

Academic Editor: Jack Barkenbus

Received: 4 November 2016; Accepted: 5 March 2017; Published: 8 March 2017

\begin{abstract}
The Chinese government has long been preoccupied with solving the problem of overloaded trucking in intercity freight systems (IFSs). The enforcement of prohibiting overloaded trucking, which enhances environmental and social performance of sustainability, has not progressed well, as it raises transport costs and lowers economic performance, and cannot improve the overall performance of sustainability. It is, thus, necessary to find a way to eliminate overloaded trucking without undermining the overall performance of sustainability. A modal shift is a potential way to achieve freight sustainability, by encouraging greater use of more efficient transport modes. This paper develops a system dynamics model to perform a long-term evaluation of alternative modal shift policies with trucks meeting the statutory limit, and then identified effective policies, whereby the increasing sustainability of IFSs could be achieved. The proposed model was applied to a specific case in China. The results show that the effective modal shift policy is to construct a Class I railway to shift freight away from highways. A discussion is then proposed, based on an analysis of different parameter setting scenarios regarding more general situations.
\end{abstract}

Keywords: overloaded trucking; freight sustainability; modal shift; system dynamics; China

\section{Introduction}

Sustainability of transportation systems has become a growing area of interest in practice and research. Institutions and researchers have proposed different definitions of sustainability of transportation systems, and have shown a consensus, that sustainability of transportation systems requires holistic triple bottom line accounting, including the economic, social, and environmental properties of transportation [1]. Although there is no standard definition [1], Cormier and Gilbert [2] still recommend the definition proposed by the Centre for Sustainable Transportation (CST) in Canada, because this definition has a broad scope and recognizes specific transportation issues. According to this definition, the sustainability of a transportation system requires a transportation system to: (1) allow the basic access and development needs of individuals, companies, and society to be safely met; (2) operate fairly and efficiently, offering a choice of transport modes and supporting a competitive economy; and (3) limit emissions and waste within the planet's ability to absorb them [2]. Sustainability of transportation systems could be evaluated by a set of indicators, among which the most common indicators include transport cost, transport time, emissions, noise, traffic congestion, and safety [3]. 
It is worth noting that there are differentiated concepts of "sustainable transportation" and "sustainable development of transportation" relating to the concept of sustainability of transportation. The concept of "sustainable transportation" emphasizes the effects of transport sustainability, while the concept of "sustainable development of transportation" is understood as the process of evolution in the transport sector with the property of increasing sustainability [4]. The difference between the two concepts is characterized by Goldman and Gorham [5] as "sustainability as an end-state vision" and "sustainability as a pathway", respectively. The meaning of freight sustainability in this study refers to "sustainability as a pathway"; namely, the achievement of better sustainability than that of the current practice, in terms of improvements to sustainable transport indicators.

Intercity freight, which accounts for a portion of China's overall domestic transportation, has received increasing attention, as it is recognized as one of the major considerations of the nation's sustainable development. A common and serious problem with China's intercity freight systems (IFSs) is overloaded trucking, which preoccupies the Chinese government because it enhances the economic performance of IFSs at the expense of environmental and social performance. On the one hand, overloaded trucks can cause deterioration of roads, vehicle maneuvering difficulties, and safety issues [6], which drive sustainability in the opposite direction than the positive mobility effects. On the other hand, however, overloaded trucking enhances economic performance, as it significantly lowers freight owners' transport costs of materials, and, further, their production costs of final goods. This is why, although the statutory limit of truck weight was explicitly regulated by the Chinese government in 2004, overloaded trucking still prevails in many regions, especially in those with resource-intensive industries [7]. Some studies focusing on overloaded trucking in China have also, to some extent, verified this phenomenon. Hang and Li [7] concluded that the moderate weight regulation, by which truck weight is allowed to exceed the statutory limit to a moderate degree, is the most appropriate option to reduce transport and pavement maintenance costs. Liu and $\mathrm{Mu}$ [8] further investigated the influences of overloaded trucking on the sustainability of highway freight systems. The results showed that the best truck weight regulation for sustainability depends on the relative importance of economic issues compared with social and environmental issues, and that overloaded trucking is a necessary choice (unless the economic issues are unimportant). In this context, decision-makers would face the predicament of policy enforcement, because permitting overloaded trucking violates the state's regulation. It is, thus, important to come up with a solution, whereby overloaded trucking can be eliminated without undermining the overall performance of the sustainability of IFSs.

A modal shift involves using efficient modes of transportation (e.g., rail and water) more often than less efficient modes (e.g., truck and air) [9]. A modal shift can be achieved using fiscal measures (e.g., rail freight funding or road freight taxation), regulatory measures (e.g., regulation on truck weight or truck size, traffic control), and infrastructure construction investment (e.g., constructing new rail infrastructure or improving existing rail infrastructure) [10]. Researchers have proven that an appropriate modal shift in policy can effectively lower the average transport cost, reduce transport emissions and congestion, and enhance traffic safety [11-14], which are all important issues in freight sustainability. Therefore, shifting away from trucks would be a potential way to achieve an increasing sustainability of IFSs, with the premise of trucks meeting the statutory limit.

The objective of this study was to evaluate and compare the sustainable effects of alternative modal shift policies with trucks meeting the statutory limit in the long-term, and then to identify the effective ones, by which increasing sustainability of IFSs could be achieved. The remainder of the paper is structured as follows: Section 2 presents a literature review. Section 3 proposes a policy evaluation model, including model framework and model development. Section 4 applies the proposed model to a specific case in China. Section 5 formulates several optional modal shift policies for the case. Section 6 evaluates the long-term sustainable effects of the formulated policies with the model and identifies the effective modal shift policies, and then includes a discussion based on an analysis of different parameter-setting scenarios regarding more general circumstances. Section 7 draws conclusions and suggests further research. 


\section{Literature Review}

The literature review is presented following two basic streams. The first stream investigates the existing methods for freight sustainability evaluation, and then highlights the applicability of system dynamics (SD), an important branch of systems-based approaches, to the objective of this study. The second stream introduces SD, as well as its applications, to freight transportation. The shortcomings of these applications are then analyzed, and the contributions of this study are underlined.

\subsection{Methods for Freight Sustainability Assessment}

Alternative methods were used for freight sustainability evaluation [15,16], among which optimization models [17-19] and simulation-based methods [20-22] were extensively used in the assessment of different aspects of freight sustainability. However, these methods are not sufficiently applicable for analyzing the long-term sustainable effects of modal shift policies with the goal of solving the overloaded trucking problem. The reasons for this are threefold:

- The above-mentioned methodologies presuppose that the exogenous stimuli, e.g., policy activities, can be clearly distinguished and, thereafter, examine the effects of the stimuli separately [23]. Regarding the problem of this study, solving the overloaded trucking problem involves changing the truck payload, which gives rise to simultaneous variations in multiple determinants of a freight system, such as transport cost, transport time, and truck traffic volume, which cannot be clearly and individually separated and analyzed.

- The strategic evaluation of freight sustainability should be performed at the macro level of freight systems, which requires including components of freight systems, as comprehensively as possible. This requirement leads to a method that facilitates accommodating a wide range of components, while simplifying the details of the components. In contrast, optimization- and simulation-based methods are characterized as high-resolution in components' details but as low-resolution in the coverage of components [24]. Consequently, these methods are more appropriate for the analysis of sub-systems of freight systems or of sub-objectives of freight sustainability.

- The assessment of the effect of modal shift policies on the overall performance of sustainability needs to, simultaneously, take into account economic, social, and environmental objectives. The optimization- and simulation-based methods, intended to optimize individual sub-objectives, cannot reliably evaluate the overall sustainable performance of a freight system, even when these methods are used in such a way that one model's results feed into another model's assumption [25]. In other words, these methods are generally inadequate for the assessment of the overall performance of sustainability when the whole is greater than the sum of its parts; namely, freight sustainability as the emergence of intertwining factors, including freight activities, policies, and time.

The sustainable effects of modal shift policies on IFSs arise from a set of coupled causes and last over time. Looking too narrowly at a particular cause or changes within a particular time, without systematically considering the sustainable effects, would lead to solutions that merely serve to move the issues of sustainability around, rather than improve the system as a whole. From this point of view, the methodological priority should be toward a systems-based approach [26], which focuses on the system's evolution that stems from interactions and feedback among components of the system and is capable of comprehensively and dynamically analyzing policy effects.

Regarding the applications of systems-based approaches to freight sustainability evaluation, Richardson [27] employed a method based on influence diagramming to provide frameworks illustrating the interactions among influence indicators of freight sustainability. However, this study did not suggest any method for quantifying the relationships among the variables and indicators. Ülengin et al. [26] developed a structural equation model to assess the consequences of possible policies on Turkey's passenger and freight transportation system. The model quantifies interrelations among a 
series of variables that reflect alternative sustainable issues; however, it stresses indicators regarding environmental and social issues, with little consideration for economic issues, such as transport costs and transport time, which are important for freight owners and carriers. Maheshwari et al. [28] built a dynamic model, which was derived by referring to the predator-prey models of biology, to capture the interdependent behavior of transportation, economics, and environmental systems over time. However, the model did not further account for the interrelations among the components within the respective systems; thus, the detailed effects of the policies could not be analyzed.

In this study, the method we employed was SD, which is another important branch of systems-based approaches. SD is well suited for the objective of this study for the following reasons:

- The essence of the problem of overloaded trucking lies in the interactions of different agents' (e.g., freight owners, infrastructure operators, and the government) decisions, based on their own interests. SD is useful in understanding these interactions by setting both multiple variables representing the behavior of those agents and equations between variables that reflect the interdependency of those agents.

- The objective of this study is to evaluate policies' effects on sustainability, regarding which both economic effects and social and environmental effects should be considered simultaneously. SD allows the cost-benefit analysis approach to be integrated [7], which enables a consistent assessment of policies by converting both economic effects and social and environmental effects into monetary equivalents; thus, it is suitable for evaluating global effects of modal shift policies on freight sustainability.

- The nature of this research is policy evaluation, which is in the strategic horizon that the long-term effects of policies are to be assessed. SD has the advantage in policy evaluation of not only analyzing the ultimate effects of policies over a long time period, but also providing a time path of policies' impacts on systems [24].

\subsection{SD and Applications to Freight Transportation}

SD was initially developed by Forrester from Massachusetts Institute of Technology in the 1950s and 1960s. It uses a standard causal loop approach to develop a qualitative model of a system, which is then transformed into a quantitative stock-flow model that consists of stocks, flows, converters, and feedback loops. The SD approach is becoming increasingly used in a hierarchical manner, which allows systems and policies to interact across space and time [29]. Thus, it is a useful decision-making and policy evaluation tool due to its ability of interpreting the past behavior of systems and forecasting policies' effects on systems.

SD was first applied in transportation in the 1990s for passenger transportation, and later for freight transportation. Abbas and Bell [30] first confirmed the applicability of SD for transportation modeling and listed twelve advantages of the approach compared to traditional transport modeling. Shepherd [29] recently proposed a comprehensive review of SD models applied to transportation within the last twenty years. However, the literature applying SD to freight transportation focuses, respectively, on a single issue of sustainability, such as carbon emission [31-33], land use [34], pavement condition [7,35], traffic safety [36], and congestion [37,38], with little discussion on the integrated effects of the above-mentioned issues, namely, freight sustainability. Moreover, most existing literature does not consider the problem of overloaded trucking, except the research by Hang and Li [7], but the objective of this research is to investigate the impacts of overloaded trucking on transport and pavement maintenance costs, not on freight sustainability. Overloaded trucking gives rise to simultaneous changes in IFSs' performance on the above-mentioned sustainable issues. The dynamic mechanism of how overloaded trucking and modal shift policies influence the overall performance of sustainability needs to be investigated.

This research advances the literature related to freight transportation by solving the problem of overloaded trucking, meanwhile achieving the increasing sustainability of IFSs via an SD approach. In this study, we developed an SD model to evaluate the sustainable effects of potential modal 
shift solutions in which trucks meet the statutory limit; we then compared the effects with those of the current practice in which trucks are overloaded and identified the effective modal shift policies for increasing sustainability in terms of the reduction of IFSs' total costs, including economic, environmental, and social costs. The results of this study provide some insight into the reciprocal mechanism between modal shift policies and the sustainable performance of IFSs. The SD model provides the decision-makers with a tool for developing the appropriate and feasible modal shift policies to achieve increasing sustainability of IFSs with the premise of eliminating overloaded trucking.

\section{Methodology}

Before the SD model is proposed, the common and self-defined abbreviations used are listed in Table 1.

Table 1. Abbreviations used in the system dynamics (SD) model.

\begin{tabular}{cccc}
\hline Abbreviations & Comments & Abbreviations & Comments \\
\hline IFS & Intercity freight system & VOT & Value of time \\
\hline SD & System dynamics & PCU & Passenger car unit \\
\hline CDRL & Code for design of railway line & RWR & Rigid weight regulation \\
\hline FGM & Freight generation module & MSR & Modal shift from road towards railway \\
\hline FEM & Fleet evolution module & TCC & Total cumulative cost \\
\hline FIM & Freight infrastructures module & CEC & Cumulative economic cost \\
\hline FTM & Freight time module & CSC & Cumulative social cost \\
\hline MSM & Modal split module & CGC & Cumulative generalized cost \\
\hline PEM & Policy evaluation module & CTPC & Cumulative truck purchasing cost \\
\hline PPI & $\begin{array}{c}\text { Pavement } \\
\text { performance indicator }\end{array}$ & CPMC & $\begin{array}{c}\text { Cumulative pavement maintenance cost } \\
\text { SDHAP }\end{array}$ \\
$\begin{array}{c}\text { Specifications for design of } \\
\text { highway asphalt pavement }\end{array}$ & CGAC & $\begin{array}{c}\text { Cumulative greenhouse gas and air } \\
\text { pollutant emissions cost }\end{array}$ \\
\hline RM & Restorative maintenance & CTAC & Cumulative traffic accidents cost \\
\hline CM & Corrective maintenance & CIRI & $\begin{array}{c}\text { Cumulative investments on railway } \\
\text { infrastructure and locomotives }\end{array}$ \\
\hline
\end{tabular}

\subsection{Problem Description and Hypotheses of the Model}

The generic representation of a typical IFS in China is shown in Figure 1. The most common transport infrastructures are highways, including an express highway and a regular highway. The express highway is enclosed, charging the passing trucks by weight, and overloaded trucks are subjected to heavy penalties; therefore, the express highway deters all of the overloaded trucks. The regular highway is open to all vehicles and free of charge, with traffic police performing random inspections on overloaded trucks during the day. Thus, most of the overloaded trucks choose to use the regular highway at night to avoid the traffic police, causing traffic safety problems and severe damage to the pavement. Except for highways, the railway should also be considered. However, the railway is not equipped as commonly as highways in most of the IFSs in China. Thus, if an IFS is not equipped with the railway, the construction of a new railway is considered. The railway is differentiated as Class III, Class II, and Class I according to the Code for Design of Railway Line (CDRL) published by the China Railway Corporation [39], with significant differences in technical specifications of both railway lines and locomotives. 


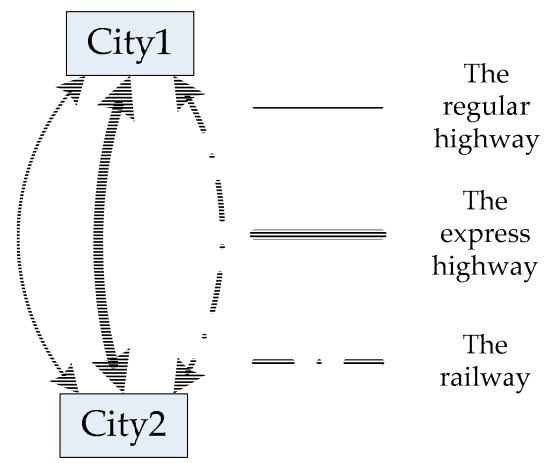

Figure 1. Generic representation of an intercity freight system.

This study targets the problem of overloaded trucking in IFSs in China, with the aim of eliminating overloaded trucking and, meanwhile, achieving increasing sustainability via modal shift policies in the long term. Based on this objective, the following assumptions are adopted:

(1) A modal shift policy is fixed throughout the simulation period once it is implemented, without considering the situation that the policy is altered or aborted.

(2) The model considers only highway pavement damage from heavy-duty trucks while neglecting that from small passenger cars because of the minor influences of passenger cars on highway pavement. Regarding the maintenance of infrastructures, the model excludes the situation of delayed maintenance operations due to a budget shortfall [35] and assumes that maintenance operations initiated in a year can be accomplished within the year.

(3) The model assumes that new vehicles are to be put into service instantly, without considering the delay in the processes of sales and delivery of the new vehicles.

\subsection{Model Framework}

The SD model is developed in a modular manner, with the main elemental modules and their reciprocal links depicted in Figure 2.

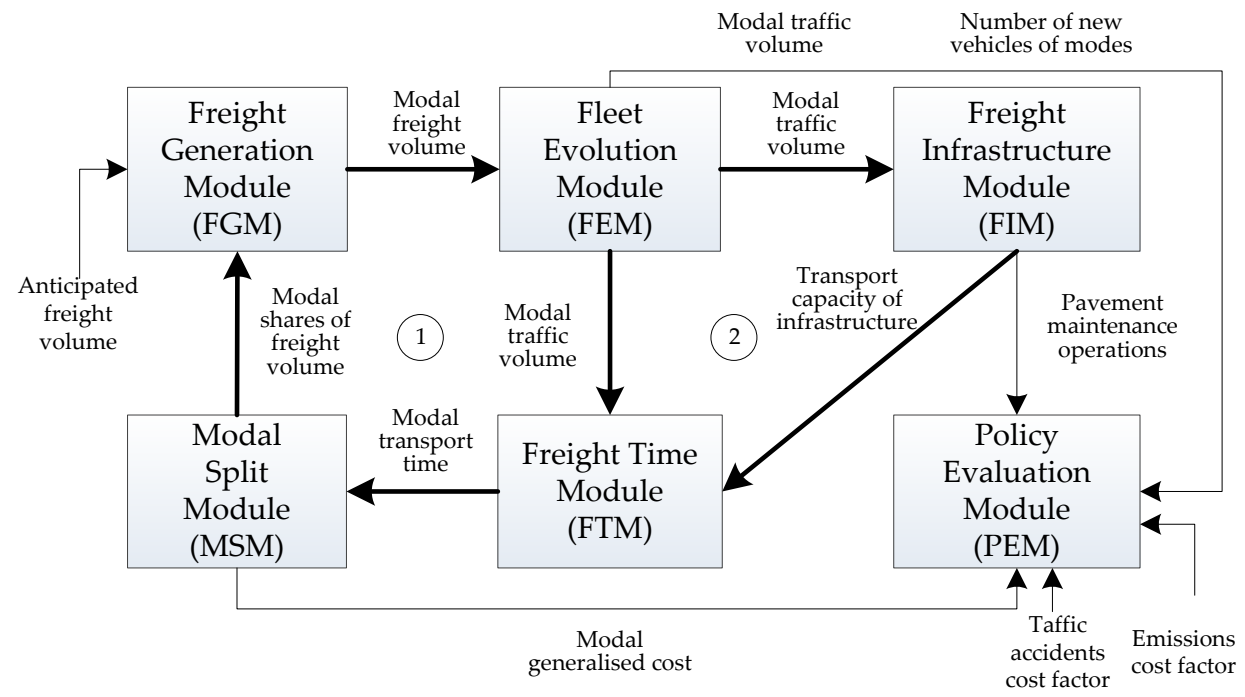

Figure 2. Framework of the SD model.

The theoretical basis supporting the development of the framework is the classical four-step model, a predominant framework for freight transport modeling [24]. The model framework is composed of 
six interrelated modules, including the freight generation module (FGM), the fleet evolution module (FEM), the freight infrastructures module (FIM), the freight time module (FTM), the modal split module (MSM), and the policy evaluation module (PEM), with each one dedicated to one specific function. The whole system evolves year by year as a consequence of the reciprocal effects among modules. In general, the sustainability of an IFS, evaluated in the PEM, depends on its freight activities that are determined by a complex mechanism that functions through two feedback loops coving the other five modules, marked as Loops 1 and 2 in Figure 2. To be specific, in feedback Loop 1, according to the modal share provided by the MSM, the modal freight volume is determined by the FGM and is then converted into the modal traffic volume by the FEM. The modal traffic volume influences the congestion level and transport time of a mode (calculated in the FTM), which are the important determinants of the modal share of the next year. In Feedback Loop 2, the modal traffic (calculated by the FEM) causes wear and tear to the infrastructure and leads to changes in the infrastructure's capacity (calculated by the FIM), which influence the congestion level, as well as transport time of a mode (calculated by the FTM), and further influence the modal share (calculated by the MSM) and modal traffic volume of the next year. As a result, the sustainability of an IFS is determined by the dynamic course in which freight activities are intertwined within the feedback loops.

\subsection{Model Development}

\subsubsection{The Freight Generation Module}

This module functions to forecast the total freight volume of an IFS of a year first, then assigns it to the alternative modes. The total freight volume is influenced by multiple complicated factors, such as the national and regional economy, industry situations, etc. Considering that it would make the model too complicated by taking all of these factors into the model and forecasting endogenously, the model applies an exogenous estimation, namely taking the forecasting results from other models as the input of this model. After the total freight volume is determined, freight distribution among the alternative modes is implemented by the following two steps:

Step one: The distribution of the total freight volume between the highway system and the railway system, based on the respective modal share provided by the MSM. In this step, the freight volume of the railway system is determined considering, first, the rigid restriction of the maximum capacity on the railway system, which is different from the highway system, in which the truck traffic volume of a highway is allowed to exceed its maximum capacity. With this constraint, this module calculates the scheduled freight volume of the railway first, then compares the scheduled freight volume with the maximum capacity of the railway, and the actual freight volume of the railway is the lesser of them. The function is as follows:

$$
f_{R}(t)=\min \left(f(t) \times p_{R}(t), Q_{R}\right)
$$

where $f_{R}(t)$ is the freight volume of the railway system in year $t, f(t)$ is the freight volume of the total freight volume of an IFS, $p_{R}(t)$, provided by the MSM, is the modal share of the railway, and $Q_{R}$ is the maximum capacity of the railway.

The freight volume of the highway system is then obtained by removing the railway freight volume from the total freight volume.

Step two: The freight distribution within the highway system. In this step, the freight volume of the highway system is further assigned to the express highway and the regular highway based on the corresponding modal share. The function is as follows:

$$
f_{H_{k}}(t)=\left(f(t)-f_{R}(t)\right) \times p_{H_{k}}(t)
$$

where $f_{H_{k}}(t)$ is the freight volume of highway $k$ in year $t$, and $p_{H_{k}}(t)$, provided by the MSM, is the modal share of highway $k$. 


\subsubsection{The Fleet Evolution Module}

After the modal freight volume is generated, a fleet of vehicles is needed to transport the freight. This module aims to assess the number of scrap vehicles and new vehicles each year, serving for the PEM for calculating the vehicles' purchasing cost. The approach adopted in this module is the classic scrap-and-sales model [33]. Specifically, this module first estimates the modal vehicle stock needed to fulfill transport demands according to the vehicle utilization rate and the modal traffic volume that is transformed from the modal freight volume, which, then, compares it with the remaining vehicle stock to obtain the number of new vehicles of a mode. The function is as follows:

$$
n_{x}(t)=N_{x}(t)-\sum_{y} \operatorname{Stock}_{x}(t, y)
$$

where $n_{x}(t)$ is the number of new vehicles of mode $x$ in year $t, N_{x}(t)$ is the vehicle stock fulfilling transport demands. Stock $(t, y)$ is the remaining stock of vehicles with an age of $y$ years in year $t$, with the function of

$$
\operatorname{Stock}_{x}(t, y)=\operatorname{Stock}_{x}(t-1, y-1)-\operatorname{Scrap}_{x}(t-1, y-1)
$$

where $\operatorname{Scrap}_{x}(t-1, y-1)$ is the number of scrap vehicles with an age of $y-1$ years in year $t-1$. Regarding trucks on highways, $\operatorname{Scrap}_{x}(t, y)$ depends on the scrap probability $\phi_{y}$ that features a Weibull distribution in the form of

$$
\left\{\begin{array}{l}
\phi_{y}=1-e^{a_{j}} \\
a_{j}=-\left(\frac{y-1+b_{j}}{L_{j}}\right)^{b_{j}}
\end{array}\right.
$$

where $L_{j}$ is the average value of the maximum useful life span of trucks, $b_{j}$ is the parameter that determines the growth rate of scrap probability as age of trucks increases. Both $b_{j}$ and $L_{j}$ are related to truck type $j$. Hao et al. [40] obtained the values of both parameters through a regression analysis on the statistics of scrapped vehicles in China, including light, medium, and heavy duty trucks, and illustrated the resulting Weibull distribution under different values of both parameters. If trucks are overloaded, more serious wear and tear to trucks is caused, leading to a smaller value of $L_{j}$ and a higher value of $\phi_{y}$.

Regarding freight trains on the railway, the simulation of scrap and sales is simpler as there are no overloaded freight trains of which the usage duration varies significantly. The simulation functions as a sort of conveyor where freight trains are transferred year by year from an age class to the subsequent one and are dropped out after the maximum usage period of 20 years regulated by the China Railway Corporation.

\subsubsection{The Freight Infrastructures Module}

The modal traffic of freight vehicles causes damage to the infrastructure. This module addresses simulating the deterioration and maintenance dynamics of infrastructures and, based on which, to estimate the average transport capacity of infrastructures. Regarding the maintenance operations of the railway, this module considers only regular maintenance, since most of the wear and tear to the railway is regular without extra damage from overloaded freight trains, which are strictly forbidden by the China Railway Corporation due to their fatal damage to railway lines, as well as rail freight safety.

The deterioration and maintenance dynamics of highway pavements is much more complicated than that of the railway due to the existence of overloaded trucks with nonlinear characteristics in their damage to pavement. In China, the pavement condition is quantified by the pavement performance indicator (PPI), defined by the Specifications for Design of Highway Asphalt Pavement (SDHAP) published by the Ministry of Transport of China [41]. The highway operator determines alternative maintenance operations based on the value of PPI, and the performance thresholds and maintenance effects of these operations are shown in Table 2. 
Table 2. Performance thresholds and maintenance effects of maintenance operations.

\begin{tabular}{ccc}
\hline Maintenance Operations & Thresholds of PPI Values & Maintenance Effects \\
\hline Restorative Maintenance $(\mathrm{RM})$ & $P P \hat{I}_{H_{k}}(t) \leq 45, k \in\{1,2\}$ & $P P I_{H_{k}}^{*}(t)=100, k \in\{1,2\}$ \\
Corrective Maintenance $(\mathrm{CM})$ & $45<P P \hat{I}_{H_{k}}(t) \leq 65, k \in\{1,2\}$ & $P P I_{H_{k}}^{*}(t)=85, k \in\{1,2\}$ \\
Do Nothing $(\mathrm{DN})$ & $P P \hat{I}_{H_{k}}(t)>65, k \in\{1,2\}$ & - \\
\hline
\end{tabular}

In Table 2, $P P \hat{I}_{H_{k}}(t)$ and $P P I_{H_{k}}^{*}(t)$ are, respectively, the PPI value of highway $k$ before and after pavement maintenance in year $t$. The value of $P P \hat{I}_{H_{k}}(t)$, ranging from zero (when the pavement is at its worst condition) to 100 (when the pavement is at its best condition), is calculated by the following traditional pavement deterioration formula [42]:

$$
P P \hat{I}_{H_{k}}(t)=P P I_{H_{k}}^{*}(t-1) \times\left(1-e^{-\alpha^{k^{\beta^{k}}}}\right)
$$

where $\alpha^{k}$ and $\beta^{k}$ are dependent on the actual usage duration of highway $k$, which is determined by the allowable cumulative equivalent axles that the pavement can bear and the equivalent axles of truck traffic with a certain truck weight. In the context in which trucks on a highway are overloaded, the equivalent axles of truck traffic grow rapidly, causing a sharp decline in the actual duration the highway is used and the extra maintenance operations.

The second function of this module is to calculate the average transport capacity of an infrastructure, which is updated each year of simulation on the basis of the infrastructure deterioration and maintenance operation determined by the first function. The railway capacity is expressed in tons per year, and the maximum value is regulated by the CDRL [39]. Considering that regular maintenance of the railway is always performed, the average capacity of the railway is thus assumed to be at its maximum. The highway capacity is expressed in passenger car units (PCU) $\times$ kilometers, in which the PCU, defined by the SDHAP [41], is used in consideration that a highway is used by both large freight trucks and small passenger cars. The average capacity of a highway is measured by the average value of PPI within a year that reflects the average pavement condition within the year.

\subsubsection{The Freight Time Module}

This module functions to estimate the average freight time of alternative modes, which consists of freight transport time and handling time. To be specific:

(1) The average transport time is determined by the average transport speed of a mode and transport mileage. Regarding the railway transport, the average speed is related to the performance of both infrastructures (e.g., class of rail lines, electrified or not) and locomotives (e.g., engine type, traction power). While the average transport speed of highway trucks is determined by a more complicated mechanism in which the congestion level needs to be taken into account, since the truck traffic volume of a highway is allowed to exceed the maximum capacity of the highway. The greater the highway capacity, or the lesser the truck traffic volume, the lower the congestion level and, thus, the higher the average speed of trucks. This relationship is quantified by the following speed-flow function [43]:

$$
\left\{\begin{array}{l}
s_{H_{K}}(t)=\frac{\lambda_{H_{k}} \times s_{H_{k}}}{1+\left(v_{H_{k}}(t) / c_{H_{k}}(t)\right)^{b_{t}}} \\
b(t)=w_{H_{k}}+\mu_{H_{k}} \times\left(v_{H_{k}}(t) / c_{H_{k}}(t)\right)^{3}
\end{array}\right.
$$

where $s_{H_{k}}(t)$ and $S_{H_{K}}$ are, respectively, the average speed and the highest speed of trucks on highway $k$ in year $t, v_{H_{k}}(t)$ is the truck traffic volume of highway $k$ in year $t$, fed by the FEM, and $c_{H_{k}}(t)$ is the average capacity of highway $k$ in year $t$, provided by the FIM. The values of $\lambda_{H_{k}}$, $w_{H_{k}}$, and $\mu_{H_{k}}$, related with highway types, are defined by the SDHAP. 
The speed-flow function manifests an entangled situation as overload trucking is involved. On one hand, overloaded trucking gives rise to the highest speed of trucks dropping, leading to a decline in the average speed. On the other hand, overloaded trucking causes truck traffic volume to decrease, resulting in relief of congestion and an increase in the average speed.

(2) The average freight handling time, including loading, unloading, and waiting time in freight yards or warehouses, is calculated by the following function:

$$
T_{x}(t)=\frac{l_{x}(t)}{d_{1 x}(t)}+\frac{l_{x}(t)}{d_{2 x}(t)}+\hat{T_{x}}(t)
$$

where $T_{x}(t)$ is the average freight handling time of mode $x$ in year $t, l_{x}(t)$ is the average payload of freight vehicles of mode $x, d_{1 x}(t)$ and $d_{2 x}(t)$ are, respectively, loading and unloading capacities, and $\hat{T_{x}}(t)$ is the waiting time of vehicles in freight yards or warehouses. Regarding highway trucks, loading and unloading processes act as a queuing system [44], in which $\hat{T_{x}}(t)$ is determined by both the number of loading or unloading machines and the number of arriving trucks calculated based on truck traffic volume. Regarding freight trains, $\hat{T_{x}}(t)$ is the average value of the best and worst values of waiting time as railway transport is operated based on a scheduled timetable, which is obtained by the freight volume of the railway, provided by the FGM, and the traction tons of a freight train.

\subsubsection{The Modal Split Module}

Both freight time and cost are important determinants of mode choices by freight owners. Since the model works at the aggregate level, the mode choices of freight owners are embodied in this module by modal shares, which are then sent back to the FGM for freight distribution among modes. The approach supporting the development of this module is the random utility theory, which estimates the share of a mode within the current year of simulation based on the transport utility of the mode of the previous year. The model most commonly used for calculating modal shares is the logit model [45], which is in the form of

$$
p_{x}(t)=\frac{e^{-\theta \times u_{x}(t-1)}}{\sum_{x} e^{-\theta \times u_{x}(t-1)}}
$$

where $p_{x}(t)$ is the share of mode $x$ in year $t$, and $u_{x}(t-1)$ is the unit transport utility of mode $x$ in year $t-1$. For freight transport, the modal utility is mainly dependent on the unit-generalized cost, which consists of the unit freight operating cost and the unit freight time cost. To be specific:

(1) The unit freight operating cost, including unit freight transport and handling costs, is calculated by the following function:

$$
c_{x}(t)=c_{1 x}(t)+c_{2 x}(t) \times h_{x}
$$

where $c_{1 x}(t)$ is the unit freight transport cost of mode $x$ in year $t$. For highway transport, $c_{1 x}(t)$ varies with the truck payload. The higher the payload (including the payload exceeding the statutory limit in overloaded trucking), the lower the $c_{1 x}(t)$. Hang et al. [46] quantified this relationship between the unit freight transport cost and the payload of highway trucks in China. For railway transport, $c_{1 x}(t)$ is actually in terms of the price of freight service provided by the China Railway Corporation as a third party of transportation. In general, the unit freight transport cost of railway is lower than that of highway due to the scale economies of transport, even when highway trucks are overloaded. However, in circumstance that there are no feeder railways for both shippers and consignees, trucking legs to both ends of railway should be considered; then $c_{1 x}(t)$ is actually the unit intermodal transport cost. $c_{2 x}(t) \times h_{x}$ is the unit freight handling cost, which depends on the handling cost of the unit freight volume $c_{2 x}(t)$ and the handling times $h_{x}$. One of the key disadvantages of railway transport is the need to conduct multiple handling of goods if intermodal transport is involved in which trucking legs to both ends of the railway are 
needed. In this situation, the unit freight handling cost includes not only that of railway transport $\operatorname{leg} c_{2 R}(t) \times h_{R}$, but also that of highway trucking legs $c_{2 H}(t) \times h_{H}$. Therefore, the modal choice strongly depends on the handling costs, as well as on the availability of co-infrastructure.

(2) The unit freight time cost is obtained by multiplying the unit freight time and the value of time (VOT). The unit freight time, including freight transport time and handling time, is calculated by the FTM. The VOT is the monetary value assigned to a unit of time and it depends on the freight type. The higher the value of a certain type of cargoes, the higher the VOT.

\subsubsection{The Policy Evaluation Module}

This module is used to evaluate the sustainability of alternative modal shift policies on the basis of policies' influences on freight activities that are simulated by the above five modules. Referring to the sustainable indicators proposed by Haghshenas and Vaziri [3], this module transforms these indicators into consistent monetary equivalents and sorts them in two categories, economic costs and social costs, to facilitate the comparison of policy effects. To be specific:

(1) Economic costs refer to the costs paid by the agents involved directly in transport activities (e.g., freight owners, carriers), including:

- The freight generalized cost, including freight operating and time costs, provided by the MSM.

- The freight vehicles' purchasing cost, which is estimated by the vehicle price and the number of new vehicles each year fed by the FEM. It is worth noting that the purchasing cost of railway vehicles includes that of locomotives only, without that of rolling stock. This is because all of the rolling stock is under unified management of China Railway Corporation, and companies cannot buy rolling stock, but rent them from China Railway Corporation. The cost for renting rolling stock has been accounted for in the transport cost of the railway.

- The investments on the railway infrastructure, based on the condition that an IFS does not have railways; and the maintenance cost of the railway infrastructure, which has already been accounted for in the transport cost, is actually in terms of the price of freight service provided by the China Railway Corporation as a third party of transportation.

(2) Social costs refer to the costs paid by the government or the public, including:

- The highway pavement maintenance cost, calculated by the maintenance operations fed by the FIM and the corresponding costs of maintenance operations. It is worth noting that this cost is classified into social costs because it is funded by the state's fiscal department, not the highway operator.

- The traffic accidents cost, which is obtained by multiplying the modal traffic volume and a modal-accident cost factor. Particularly for highways, the value of the accidents cost factor varies with the truck weight. The higher the truck weight, the worse the maneuver of trucks, and, thus, the greater the accidents rate and the factor value.

- Greenhouse gas and air pollutants emissions costs, which are estimated individually by adopting fuel-based and distance-based approaches [47]. The general method used for both approaches is to estimate the emissions amount first by multiplying the amount of freight activities and an emission factor per unit of freight activity, then to calculate emissions costs by the marginal costs of respective emissions. Noted that if trucks are overloaded, the emissions of a single truck increase under a heavier payload, but the amount of trucking activities decreases at the same time, making the situation more complex.

- The noise cost, which is excluded in the model because most of the areas that China's IFSs cover are sparsely populated. 


\section{Model Application and Validation}

The proposed SD model was applied to a specific case in China, the Cao-Tang freight system (the intercity freight from Caofeidian to Tangshan), as shown in Figure 3. The main freight type of the case is iron ore, of which the amount consists over 90 percent of the overall freight volume, in contrast to other minor freight types (e.g., crude salt, crude sugar, and wood, etc.). Tangshan city is the largest steel industry base in China, and the iron ore the steel companies need is mainly imported from overseas and is unloaded in Caofeidian port located in Caofeidian district. There is no railway linking Caofeidian and Tangshan, although both the Caofeidian port and steel companies in Tangshan are equipped with internal railways. All of the iron ore from Caofeidian to Tangshan is transported through two highways, an express highway and a regular highway. The express highway is enclosed, with weighbridges monitoring trucks' weights, so it is used by only a small number of trucks that meet the statutory limit. The regular highway is open and free of charge, with traffic police inspecting it randomly during the day. Therefore, all of the overloaded trucks, with the average payload of 93 tons, which is far beyond the statutory limit of 35 tons, choose to use the regular highway at night when traffic police are off-duty, causing severe pavement damage and safety issues. It is urgent for the local government to come up with a modal shift solution that prevents overloaded trucking without undermining the overall sustainability of the system.

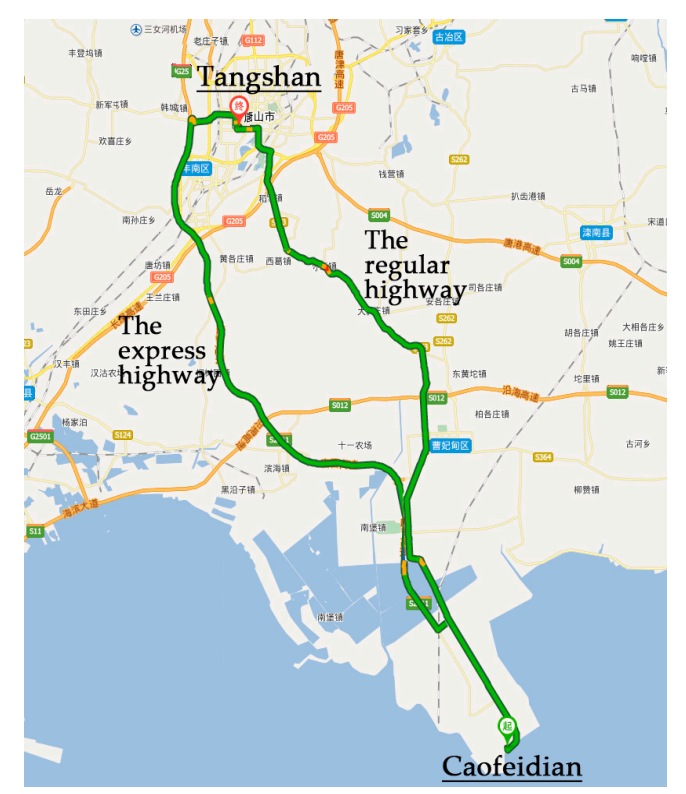

Figure 3. Illustration of the Cao-Tang freight system.

The model was applied to this case by assigning a variety of parameters specific values, which were obtained referring to both primary data derived from an onsite survey of the Cao-Tang freight system and secondary existing data derived from the peer-reviewed literature [48,49], the CDRL [39], and the SDHAP [41]. Some parameters used in the SD model of the Cao-Tang freight system are shown in Table 3.

The applied model was implemented using the Vensim software package (Ventana Systems, inc., Harvard, MA, USA), a predominant SD simulation platform, with parameters and functions transformed into model equations. Simulation runs were first conducted on historical years, from 2008, when the Caofeidian port was first operated, to 2015, for model validation. The validation process is exemplified on two variables. The results show that the simulated values of both variables are well correlated with the actual values, as shown in Figure $4 \mathrm{a}, \mathrm{b}$. The validation process was also undertaken 
for other variables, and the results are also satisfactory, which implies that the model is qualified for policy evaluation.

Table 3. Some parameters used in the SD model of the Cao-Tang freight system.

\begin{tabular}{cc} 
Parameters & Values/Units \\
\hline Initial value of the freight volume & $9.37 \times 10^{6}$ tons \\
Annual growth rate of the freight volume & $4.13 \%, 2015-2019 ; 2.92 \%, 2020-2025$ \\
Maximum cumulative equivalent axles of the express highway & $42.18 \times 10^{6}$ axles \\
Maximum cumulative equivalent axles of the regular highway & $33.00 \times 10^{6}$ axles \\
PCU of the trucks on the express highway & $7.0 \mathrm{PCU} / \mathrm{vehicle}$ \\
PCU of the trucks on the regular highway & $5.5 \mathrm{PCU} / \mathrm{vehicle}$ \\
Mileage of the express highway & $90.7 \mathrm{~km}$ \\
Mileage of the regular highway & $94.9 \mathrm{~km}$ \\
Average payload of trucks on the express highway & 35 tons $/$ vehicle \\
Average payload of trucks on the regular highway & 93 tons $/$ vehicle \\
Initial value of the railway operating cost & $0.09 \mathrm{Yuan} / \mathrm{ton} \cdot \mathrm{km}$ \\
Annual growth rate of the trucking operating cost & $2.84 \%$ \\
Annual growth rate of the railway operating cost & $5 \%$ \\
Initial value of iron ore's value of time & $70 \mathrm{Yuan} / \mathrm{hour}$ \\
Annual growth rate of iron ore's value of time & $2 \%$ \\
\hline
\end{tabular}

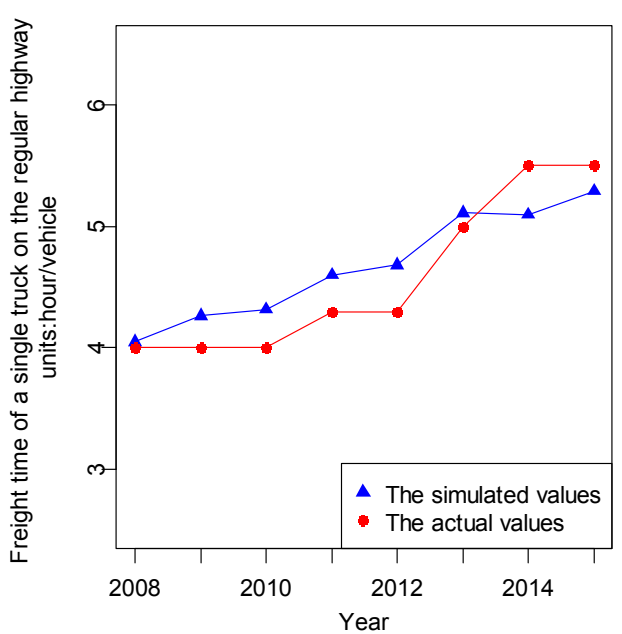

(a)

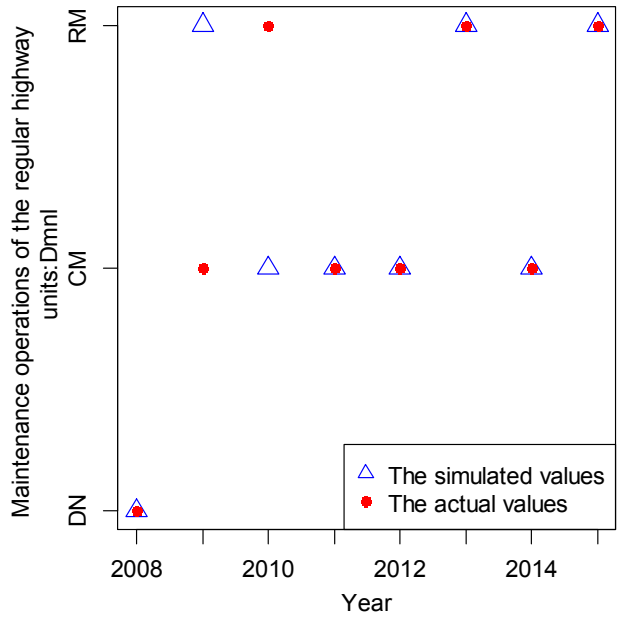

(b)

Figure 4. Model validation on (a) the freight time of a single truck on the regular highway; and (b) the maintenance operations of the regular highway.

\section{Policy Formulation}

Alternative modal shift policies were set for evaluation after the model was validated. According to the commonly used modal shift policies suggested by Woodburn et al. [10], this study considers the regulatory measure and railway infrastructure construction for the Cao-Tang freight system.

The regulatory measure refers to the rigid weight regulation (RWR) for overloaded trucks, by which all of the overloaded trucks are required to meet the statutory limit, with the expected effect that truck flow of the regular highway is diverted to the express highway. Based on the RWR, the modal shift from road towards railway (MSR) is further formulated. Railway infrastructure construction is involved regarding MSR, as there is no existing railway linking Caofeidian and Tangshan, with the expected effect that some of the freight on highways is directed to the railway, as shown in Figure 5. 


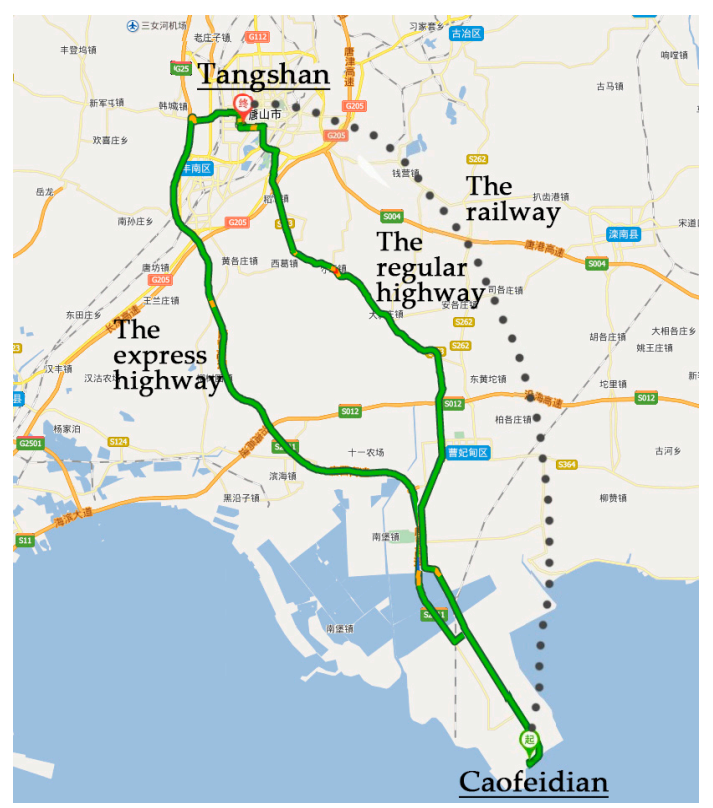

Figure 5. Illustration of the modal shift from road towards railway (MSR).

To be specific, three MSR policies were formulated, including Modal Shift from road towards Railway of Class III (MSR III), Class II (MSR II), and Class I (MSR I), according to the railway classification defined by the CDRL. Table 4 shows the technical specifications of the railway with different classes, which were obtained by consulting practitioners from the authorities' department of the Qian-Cao railway, which is exclusively used for coal transportation from Qian'an, a city adjacent to Tangshan, to Caofeidian.

Table 4. Technical specifications of the railway with different classes.

\begin{tabular}{|c|c|c|c|c|}
\hline \multicolumn{2}{|c|}{ Technical Parameters } & \multicolumn{3}{|c|}{ Values } \\
\hline & & Class III & Class II & Class I \\
\hline \multirow{6}{*}{ Lines } & Maximum capacity & $10 \times 10^{6}$ tons $/$ year & $20 \times 10^{6}$ tons $/$ year & $30 \times 10^{6}$ tons $/$ year \\
\hline & Number of tracks & Double-track & Double-track & Double-track \\
\hline & Length & $110 \mathrm{~km}$ & $110 \mathrm{~km}$ & $110 \mathrm{~km}$ \\
\hline & Construction period & 3 years & 3 years & 3 years \\
\hline & Construction cost & $13 \times 10^{6}$ Yuan $/ \mathrm{km}$ & $20 \times 10^{6}$ Yuan $/ \mathrm{km}$ & $40 \times 10^{6}$ Yuan $/ \mathrm{km}$ \\
\hline & Block system & Semi-automatic & Semi-automatic & Semi-automatic \\
\hline \multirow{4}{*}{ Locomotives } & Type & DongFeng4B & DongFeng4D & HeXieNeiran3 \\
\hline & Engine power & Diesel & Diesel & Diesel \\
\hline & Traction tons & 2500 tons & 4000 tons & 5000 tons \\
\hline & Price & $4.7 \times 10^{6}$ Yuan & $7 \times 10^{6}$ Yuan & $10.5 \times 10^{6}$ Yuan \\
\hline
\end{tabular}

Based on the formulated modal shift policies, a series of scenarios were defined as follows:

(1) The baseline, which is the scenario with a projection of the past and current trends so that the following policy scenarios can be compared with it for evaluation. As mentioned above, there is severe overloaded trucking on the regular highway. It is assumed in the baseline that this pattern will continue in the future without any policy intervention.

(2) The RWR, in which all of the overloaded trucks on the regular highway are assumed to meet the statutory limit from 2016, the starting year of the scenario. 
(3) The MSR, which includes MSR III, MSR II, and MSR I that are to be implemented individually. In the scenarios of the MSR, it is assumed that a railway is to be constructed from the starting year of 2016, and the RWR for highways is also implemented at the same time.

The simulation period of the above scenarios is set as ten years, which covers the next two five-year plans of China (the 13th five-year plan: 2016-2020, and the 14th five-year plan: 2021-2025). The model aims to calculate and compare the total cumulative cost (TCC), including the cumulative economic cost (CEC) and the cumulative social cost (CSC), within the simulation period of all the scenarios, following the principle that the policies by which increasing sustainability, in terms of a reduction of the TCC compared with the baseline, can be achieved are the effective ones.

\section{Results and Discussion}

\subsection{Sustainable Effects of the RWR}

The model first simulated both the baseline and the RWR. The sustainable effects of both scenarios are compared and analyzed as follows:

(1) The RWR causes an increase of 10.86 billion Yuan of the CEC compared with the baseline, in which:

- The cumulative truck purchasing cost (CTPC) rises by 2.53 billion Yuan, because the RWR reduces the truck payload and, thus, increases the number of trucks to fulfill the same amount of freight.

- The cumulative generalized cost (CGC) increases by 8.33 billion Yuan, most of which is contributed by the increase of the cumulative freight operating cost (7.22 billion Yuan), as the RWR counteracts the scale economies of transportation by significantly lowering the truck payload. Regarding the other constituent part of the CGC, namely the cumulative freight time cost, the results show that: (1) the cumulative freight time cost of truck traffic on the express highway increases by 1.25 billion Yuan because the RWR lowers the attractiveness of the regular highway and directs more truck traffic to the express highway, increasing the congestion and freight time of both a single truck (as shown in Figure 6a) and truck traffic; and (2) the cumulative freight time cost of truck traffic on the regular highway decreases slightly by 0.14 billion Yuan. The reason is that the freight time of a single truck remarkably decreases on one hand (as shown in Figure $6 \mathrm{~b}$ ), as the consequence of a greater capacity of the regular highway because permissible trucking hours are no longer limited to the nighttime once trucks meet the statutory limit; on the other hand, however, the truck traffic volume of the regular highway still increases (as shown in Figure 6c) by the RWR despite a lower modal share (as shown in Figure 6d), leading to a minor change in the freight time of truck traffic.

(2) The RWR contributes a reduction of 5.62 billion Yuan of the CSC compared with the baseline, in which:

- The cumulative pavement maintenance cost (CPMC) drops remarkably by 4.49 billion Yuan. On one hand, the CPMC of the express highway increases by 1.33 billion Yuan, as the result of more operation times of corrective maintenance (as shown in Figure 7a) caused by more wear of tear to the pavement from a greater truck traffic volume. On the other hand, however, the CPMC of the regular highway decreases significantly by 5.82 billion Yuan, as the RWR effectively protects the pavement and reduces the operation times of costly restorative maintenance (as shown in Figure $7 \mathrm{~b}$ ).

- $\quad$ The cumulative greenhouse gas and air pollutant emissions cost (CGAC) decreases by 0.29 billion Yuan because the reduction of emissions of a single truck with a lighter payload contributes more than the increase in the truck traffic volume. 
- The cumulative traffic accidents cost (CTAC) decreases by 0.84 billion Yuan, as the reduction in the traffic accidents rate under the RWR contributes more than the increase in the truck traffic volume.

(3) In summary, the increase in the CEC is higher than the reduction in the CSC by the RWR, leading to an increase in the TCC by 5.24 billion Yuan in contrast to the baseline. This indicates that the RWR lowers the overall performance of the sustainability of the Cao-Tang freight system and is not an effective option.

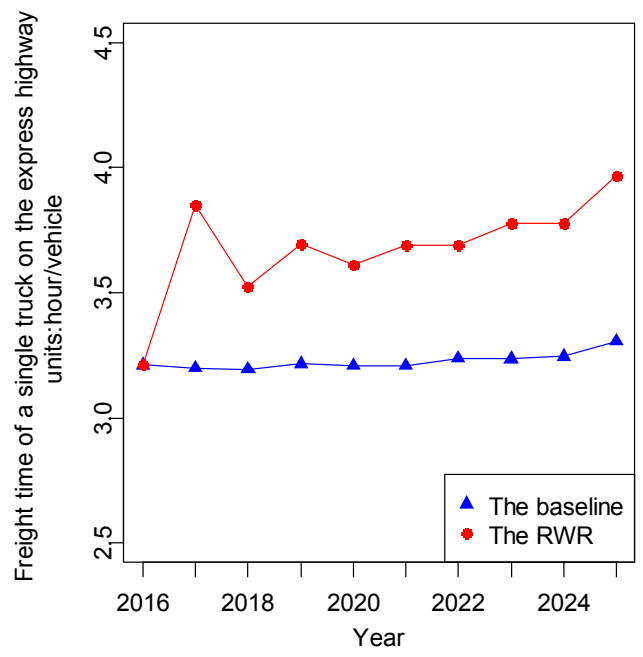

(a)

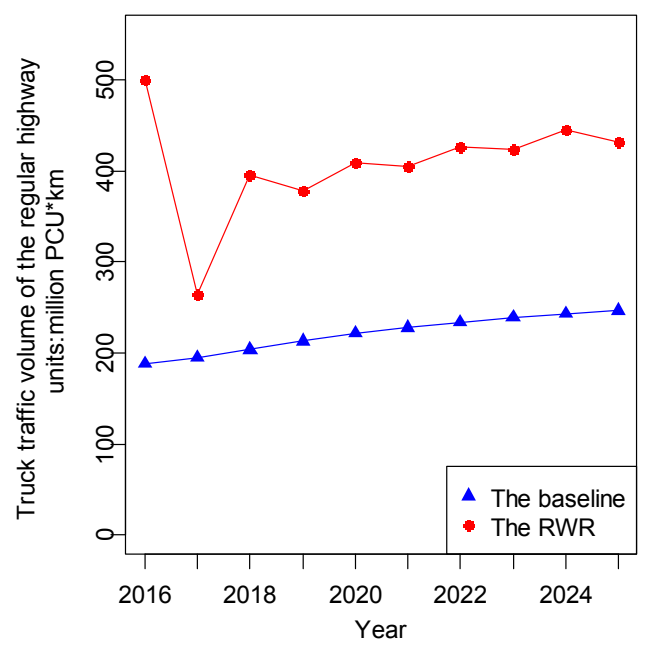

(c)

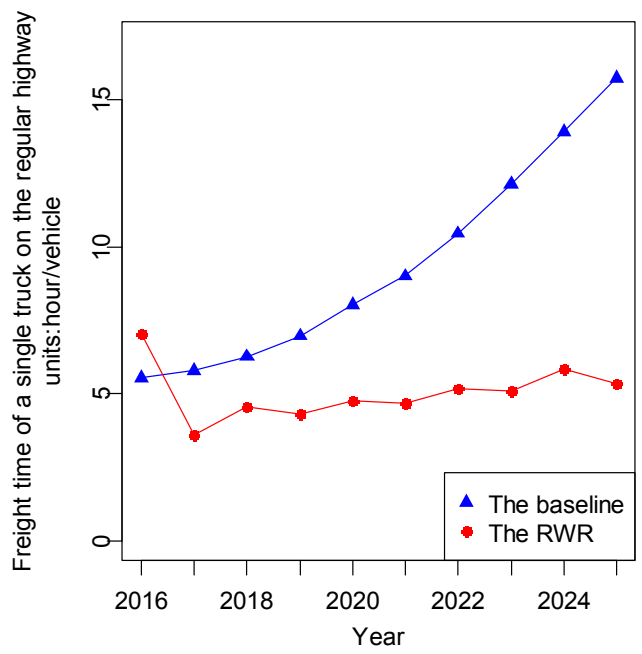

(b)

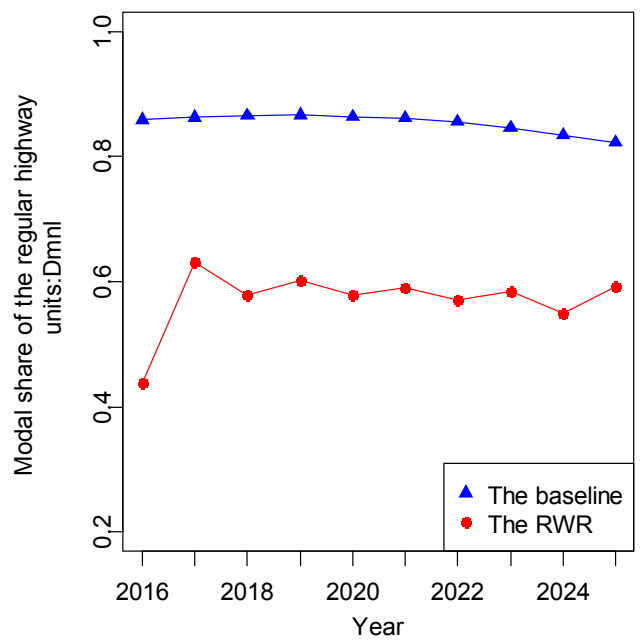

(d)

Figure 6. Scenario comparison on (a) the freight time of a single truck on the express highway; (b) the freight time of a single truck on the regular highway; (c) the truck traffic volume of the regular highway; and (d) the modal share of the regular highway. 


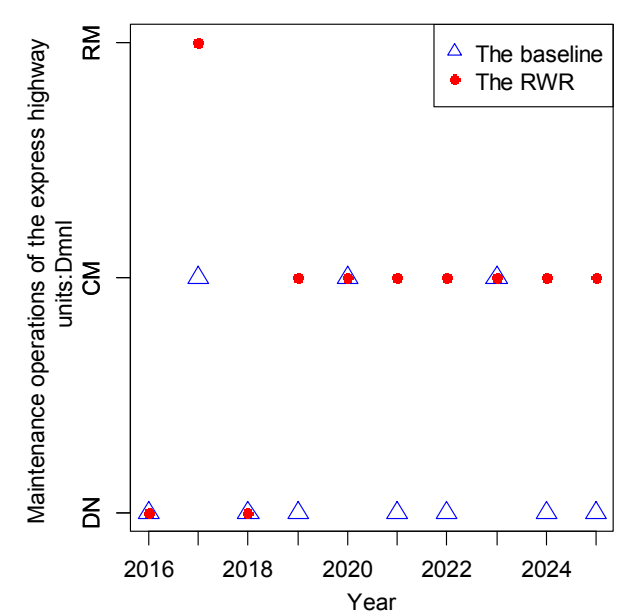

(a)

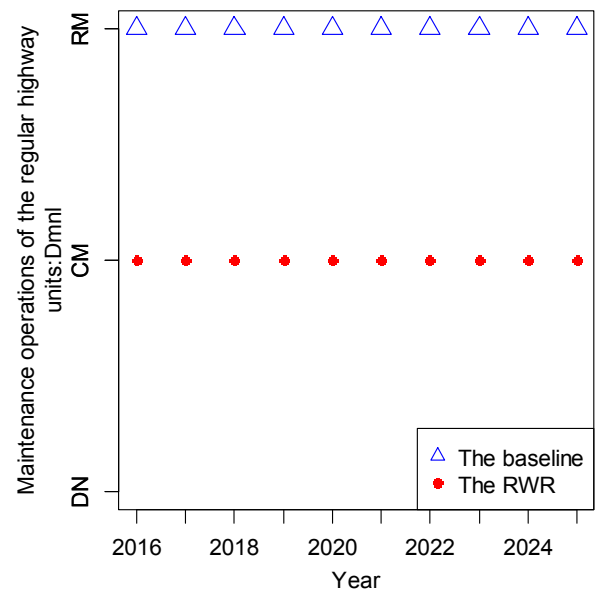

(b)

Figure 7. Scenario comparison on (a) the maintenance operations of the express highway; and (b) the maintenance operations of the regular highway.

\subsection{Sustainable Effects of the MSR}

Next, the model simulated the scenarios of MSR III, MSR II, and MSR I and compared the effects with that of the RWR and the baseline. The sustainable effects of the MSR are analyzed as follows:

(1) The CECs of the three MSR scenarios present two important features, as shown in Figure 8a. First, within the initial stage of the simulation period, the CECs of all three MSR scenarios are higher than that of the RWR, and the higher the class of the railway, the greater the CEC value. At the end of the simulation period, this trend is just the opposite. Second, the CECs of all three MSR scenarios are higher than that of the baseline. The reasons are as follows:

- The CTPCs of all three MSR scenarios are lower than that of the RWR, and the higher the class of the railway, the lower the CTPC (as shown in Figure 8b), as the railway with a higher class shifts more freight away from highways and brings about less trucks fulfilling the freight demand of highways. However, the CTPC is still higher than that of the baseline even as the railway reaches Class I. This is because the railway is under construction in the first three years and many new trucks are to be purchased under the enforcement of the RWR, leading to a fast increase in the CTPC in the first three years of the simulation period.

- The CGCs of all three MSR scenarios are lower than that of the RWR (as shown in Figure 8c), owing to involvement of the railway as a more efficient mode for both operating and time costs. However, even when the railway reaches Class I, the CGC is still higher than that of the baseline, mainly due to the contribution of CGC within the first three years when the railway is under construction.

- The cumulative investments on railway infrastructure and locomotives (CIRI), which is additional to the RWR and the baseline, is determined by the technical specifications of the railway, and the higher the class of the railway, the greater the CIRI (as shown in Figure 8d).

- Summing up the above costs, it is clear that the trends of the CECs of MSR scenarios within the first three years are mainly caused by the additional CIRIs. After the railway is put into operation, the additional CIRIs are gradually offset by both the CTPCs and the CGCs with lower growth rates.

(2) The CSCs of all three MSR scenarios are remarkably lower than that of the baseline and further lower than that of the RWR, and the higher the class of the railway, the lower the CSC (as shown in Figure 9a). The reasons are as follows: 
- The CPMCs of all three MSR scenarios are further lower than that of the RWR, due to the joint effects of the RWR that protects the pavement and the MSR that reduces the truck traffic volume of highways, and the higher the class of the railway, the lower the CPMC (as shown in Figure 9b).

- The CGACs, as well as the CTACs, of all three scenarios are lower than those of the RWR, due to the involvement of the railway as a more fuel-efficient mode and safer mode, and the higher the class of the railway, the lower the CGAC and CTAC (as show in Figure 9c,d).

(3) Summing up the CESs and the CSCs, the TCCs of the three MSR scenarios are obtained and compared with that of both the baseline and the RWR, as shown in Figure 10.

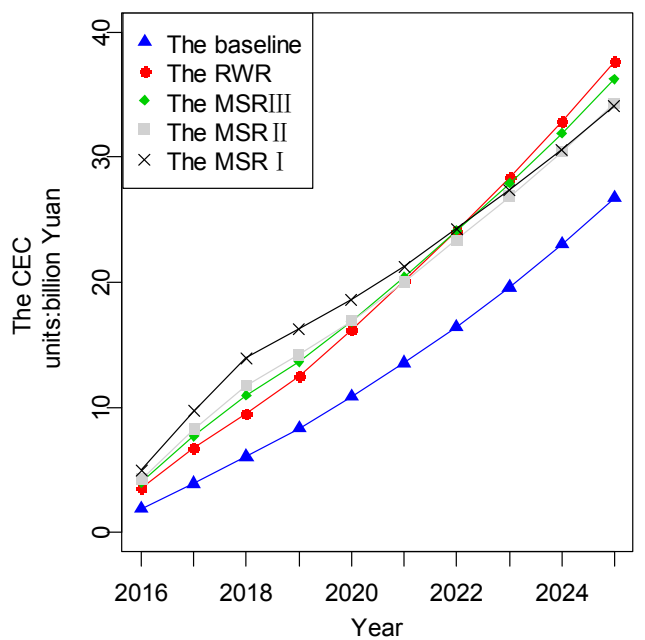

(a)

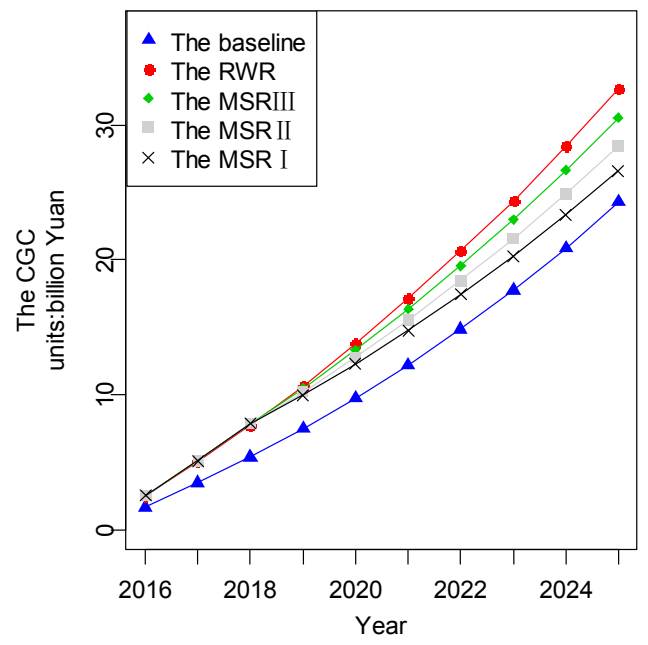

(c)

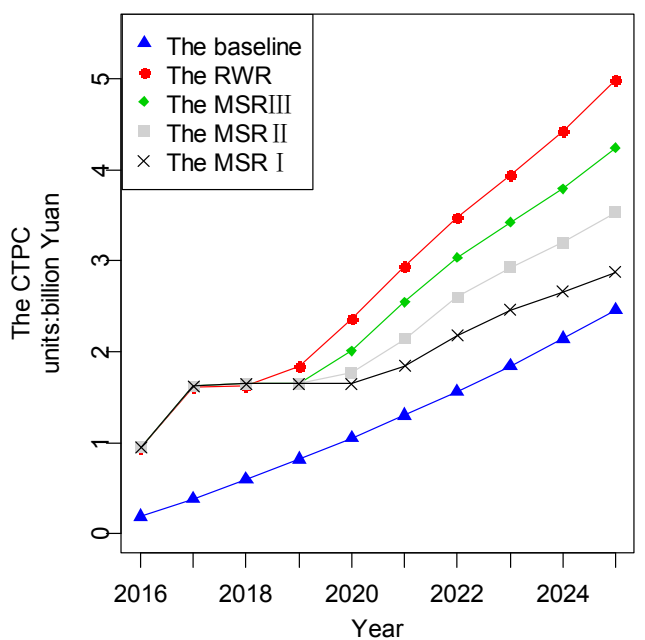

(b)

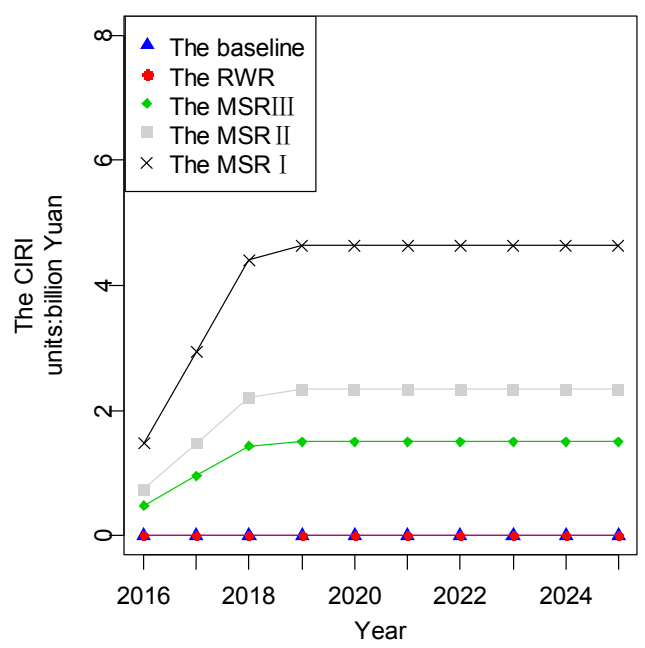

(d)

Figure 8. Scenario comparison on (a) the cumulative economic cost (CEC); (b) the cumulative truck purchasing cost (CTPC); (c) the cumulative generalized cost (CGC); and (d) the cumulative investments on railway infrastructure and locomotives (CIRI). 


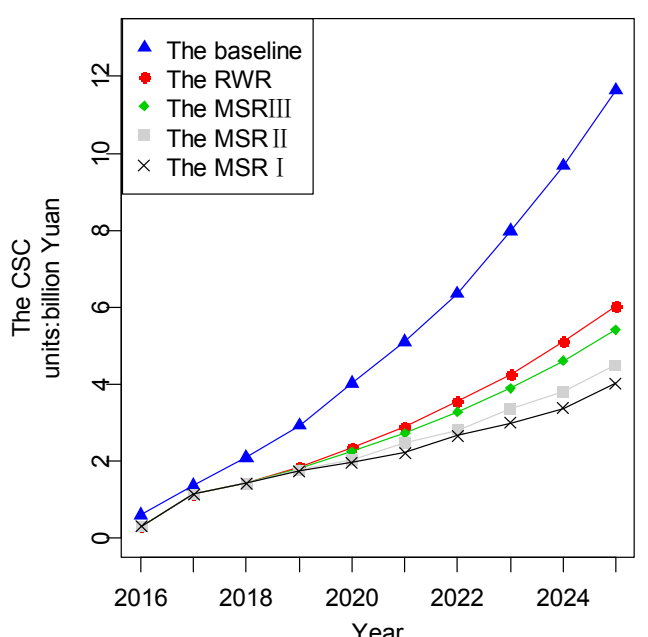

(a)

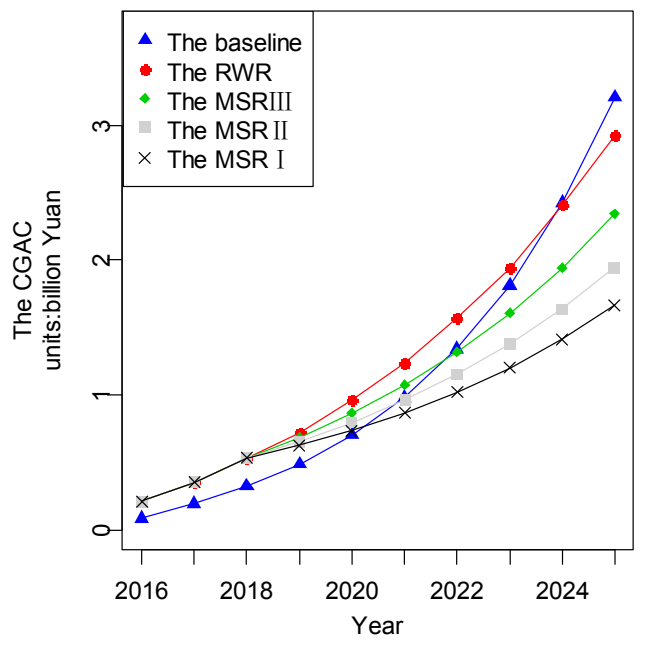

(c)

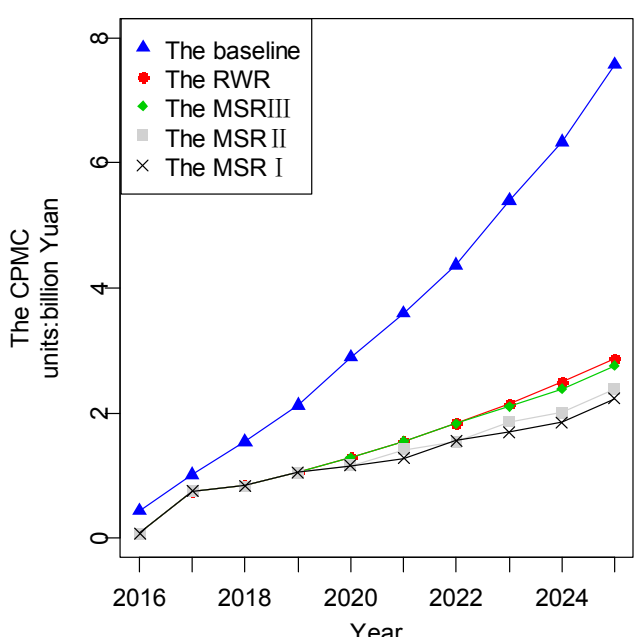

(b)

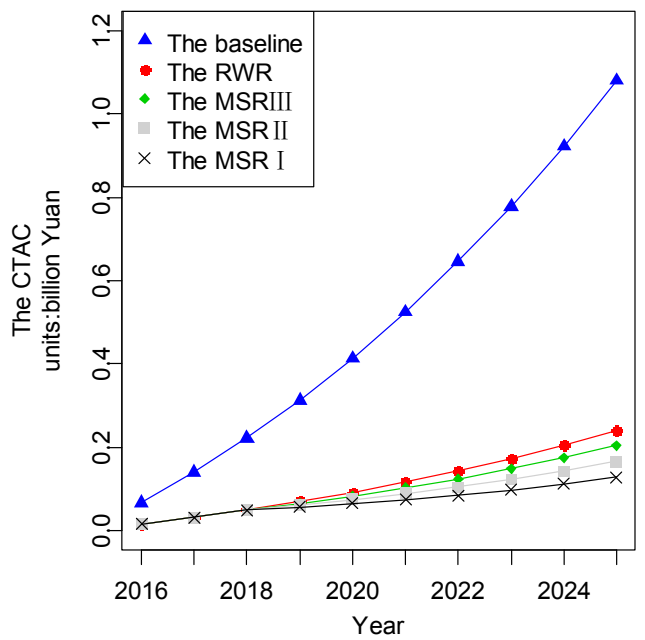

(d)

Figure 9. Scenario comparison on (a) the cumulative social cost (CSC); (b) the cumulative pavement maintenance cost (CPMC); (c) the cumulative greenhouse gas and pollutant emissions cost (CGAC); and (d) the cumulative traffic accidents cost (CTAC).

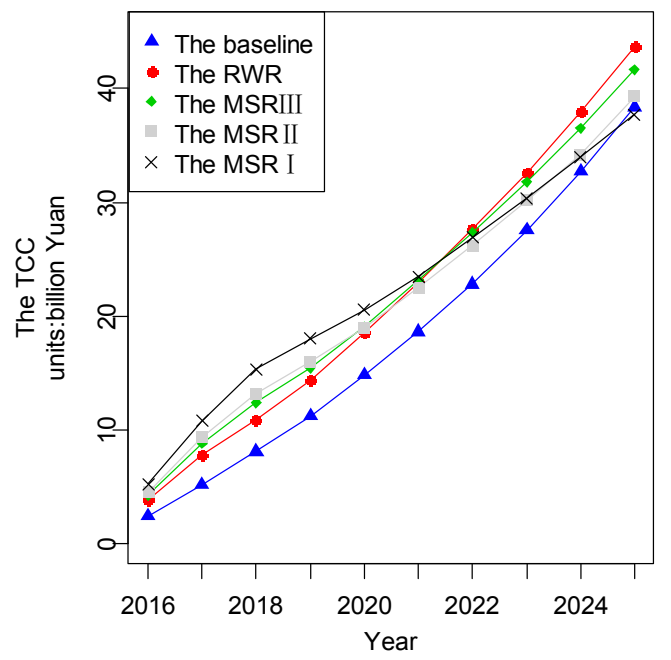

Figure 10. Scenario comparison on the total cumulative cost (TCC). 
Based on the results shown in Figure 10, the evaluation of the MSR is concluded as follows: (1) The TCCs of all three MSR scenarios within the early stage of the simulation period are higher than that of the baseline and the RWR, due to the railway not being operated and the existence of the additional CIRIs. After 2019, when the railway is put into operation, the growth rates of the TCCs of the MSR scenarios slow down, and the higher the class of the railway, the lower the growth rate of the TCC; (2) At the end of the simulation period, the TCCs of both the MSR III and the MSR II are still higher than that of the baseline, while the TCC of the MSR I is lower than that of the baseline, which indicates that the MSR I is the effective option to achieve the increasing sustainability of the Cao-Tang freight system within the preset policy evaluation period.

\subsection{Discussion}

The case analysis shows that modal shift policies simultaneously influence both the economic issues and the social issues of sustainability due to the dynamics of interdependencies between components within IFSs. The effective modal shift policies may vary as the configuration of IFSs differs regarding more general situations in terms of different parameter settings. Table 5 shows this variation of results under different parameter settings and compares results to that of the above case with the current setting. In Table 5, ineffective modal shift policies by which the sustainable effects are worse than that of the baseline are covered by the shaded box.

Table 5. Comparison of different parameters setting scenarios.

\begin{tabular}{ccccccc}
\hline & Scenarios Setting & \multicolumn{3}{c}{ Sustainable Effects of Modal Shift Policies } \\
Best $\rightarrow$ Worst
\end{tabular}

The results from four parameter-setting scenarios are discussed as follows:

(1) The first scenario changes the processing method regarding railway investments. In the case of this study, railway investments, including investments on railway infrastructure and locomotives, are included in the CEC in form of one-time investments within the first three years during which the railway infrastructure is constructed. However, it is more widely accepted from an accounting perspective that the depreciation expense of railway investments should be used. Depreciation is a method of reallocating the cost of a tangible asset over its useful life span of it being in motion. Depreciation expense of an asset is calculated based on four criteria, including: (1) cost of the asset; (2) expected salvage value; (3) estimated useful life of the asset; and (4) a method of apportioning the cost over such a life span. In this scenario, the accumulated depreciation expense of railway investments, instead of one-time investments, is included in the CEC. Parameters regarding the depreciation expense calculation are shown in Table 6, referring to the specifications for administration of fixed assets of railway transport companies, released by China Railway Corporation in 2005. 
Table 6. Parameters regarding depreciation expense of railway in China.

\begin{tabular}{cccc}
\hline & Salvage Rate & Useful Life Span & Depreciation Method \\
\hline Lines & $3 \%$ & 45 years & Straight-line \\
Locomotives & $5.04 \%$ & 20 years & Straight-line \\
\hline
\end{tabular}

Under this alternative calculation method of railway investments, the results show that both the MSR I and the MSR II are effective policies for increasing sustainability, compared to the above case with the current settings in which the sustainable effects of MSR I are only better than that of the baseline. This is because the railway depreciation is used by which high investments on railway are allocated over its long useful life, leading to lower growth rates of TCCs of MSR scenarios.

(2) The second scenario extends the simulation period of the model. It is worth noting that in the first scenario the sustainable effects of the MSR III are still worse than that of the baseline, even though the railway investments are handled as a depreciation expense. Particularly for the case of this study, the main disadvantage of multiple handling times and extra handling costs of railway transport is actually eliminated because both the Caofeidian port and steel companies in Tangshan are equipped with internal railways that can be connected seamlessly with the main railroad. The main cause is that the simulation period is preset as just 10 years, during which the advantage of railway transport for bulk freight (e.g., iron ore) cannot be fully exploited. The second scenario extends the simulation period by 10 years. The results show that the sustainable effects of the MSR III within a longer time span would be better than that of the baseline.

(3) The third scenario lowers the average overloaded ratio of trucks within the baseline. In the case of this study, the average overload ratio of trucks is very high $(165.7 \%)$ due to both the nature of iron ore with high density and the truck type, which is the largest among truck types in China. Regarding other cases, the average overloaded ratio of trucks may be lower as smaller trucks may be used. This scenario simulates this situation by assigning the average overloaded ratio of trucks in the baseline with a smaller value $(30 \%)$. Under this setting, the results show that the baseline, namely tolerating the practice of overloaded trucking, is the worst option. The sustainable effects of the RWR are even better than the baseline, not to mention the MSR scenarios. This is mainly because the increase of the pavement maintenance cost incurred by trucks with a low overloaded ratio is higher than the decrease of freight operating cost.

(4) The fourth scenario is more complicated as it simultaneously changes settings of several parameters. In the case of this study, the freight type is iron ore, which is characterized by high freight volume and overloaded ratio of trucks, but low freight VOT (value of time). Regarding other cases of IFSs, there may exists a freight type with the opposite characteristics, namely low freight volume and overloaded ratio, but high freight VOT (e.g., containers). This scenario simulates this situation by significantly raising the initial value of VOT from 70 Yuan/hour to 350 Yuan/hour and, meanwhile, reducing the initial value of freight volume from 9.37 million tons/year to 5 million tons/year and the overloaded ratio from $165.7 \%$ to $30 \%$. Furthermore, trucking legs at both ends of railway line should be considered because there are usually no feeder railways for both shippers and consignees regarding other freight types except bulk freight. Under these settings, the results show that the RWR is the best option, for the reason that is similar with that of the third scenario. The results also show that the sustainable effects of all three MSR scenarios are worse than that of the baseline. This is because of a higher handling cost caused by multiple handling times due to the existence of trucks feeding processes and, furthermore, a higher time cost is incurred due to both a higher freight handling time and a greater VOT. 


\section{Conclusions}

The sustainability of intercity freight is an important part of a nation's sustainable development. $\mathrm{SD}$ is a suitable tool for the evaluation of freight sustainability. However, most of the literature applying SD to freight transportation focuses on only one single issue of sustainability and does not consider the problem of overloaded trucking, as well as its effects on sustainability. This paper contributes to the literature by addressing the problem of sustainability of intercity freight in which overloaded trucking exists. To solve the problem of overloaded trucking of IFSs, and meanwhile to achieve increasing sustainability, an SD model was developed to evaluate and compare the sustainable effects of alternative modal shift options in the long-term, then to identify the effective ones by which a reduction in the TCC within the simulation period can be achieved. The model was applied to a specific case in China. Alternative modal shift policies were formulated for the case, including the RWR and the MSR. The results show that the RWR fails to increase the sustainability of the case, as it causes a higher TCC than that of the baseline. Regarding the MSR, the results show that the MSR I, namely constructing a railway with Class I to shift freight away from highways, is the effective option to achieve the increasing sustainability. The developed model is also applicable to other cases by modifying the values of certain parameters. Different parameter setting scenarios are designed. The results show the effective modal shift policies vary as the situation of an IFS differs.

\section{Further Research}

The SD model of this study is actually on behalf of interests of the government or society. In other words, the best modal shift policies intended to realize the increasing sustainability of IFSs are to optimize the interests of the government or society. However, this study does not consider the situation that the reduced freight volume of highway systems, caused by the decision of the government that building a railway to shift freight away from highways, would harm highway carriers in their economic interests. In fact, an IFS evolves over time as the consequence of the dynamic course of stakeholders' decisions, of which some may be made by a gaming process and be adjusted dynamically, not as assumed in this study that a policy is fixed throughout the simulation period. For instance, regarding the case of this study when the local government decides to build a railway to shift iron ore away from highways, highway carriers may take actions, e.g., reducing trucking prices, to compete with the railway transport. From this point of view, one of further studies is to address the gaming processes of two or multiple stakeholders of a freight system within SD models. SD has the advantage of greater transparency in communicating results with decision-makers, and is capable of integrating gaming tools [29]. Therefore, SD models would be more beneficial to decision-makers of IFSs once they process interactions of stakeholders more dynamically from a gaming perspective.

Acknowledgments: This research is supported by the National Natural Science Foundations of China (Grant No. 71132008 and Grant No. 71473013). The authors thank Yaoqiu Wang from Beijing Jiaotong University for his useful advice on railway transportation. The authors also thank Shengjun Yuan and Zhigang Qi from China Highway Consultants Co., Ltd. for their assistance during the investigation in Caofeidian District.

Author Contributions: Dong $\mathrm{Mu}$ and Pei Liu conceived and designed the system dynamics model of this work; Dong Mu and Pei Liu collected and analyzed the data; Pei Liu wrote the paper; and, finally, Dong Mu and Daqing Gong revised the paper. All authors have read and approved the final manuscript.

Conflicts of Interest: The authors declare no conflicts of interest.

\section{References}

1. Mihyeon Jeon, C.; Amekudzi, A. Addressing sustainability in transportation systems: Definitions, indicators, and metrics. J. Infrastruct. Syst. 2005, 11, 31-50. [CrossRef]

2. Cormier, A.; Gilbert, R. Defining Sustainable Transportation. Available online: http://cst.uwinnipeg.ca/ documents/Defining_Sustainable_2005.pdf (accessed on 21 July 2015).

3. Haghshenas, H.; Vaziri, M. Urban Sustainable transportation indicators for global comparison. Ecol. Indic. 2012, 15, 115-121. [CrossRef] 
4. Kadłubek, M. Examples of sustainable development in the area of transport. Procedia Econ. Financ. 2015, 27, 494-500. [CrossRef]

5. Goldman, T.; Gorham, R. Sustainable urban transport: Four innovative directions. Technol. Soc. 2006, 28, 261-273. [CrossRef]

6. Sosa, A.; Klvac, R.; Coates, E.; Kent, T.; Devlin, G. Improving log loading efficiency for improved sustainable transport within the Irish forest and biomass sectors. Sustainability 2015, 7, 3017-3030. [CrossRef]

7. Hang, W.; Li, X. Application of system dynamics for evaluating truck weight regulations. Transp. Policy 2010, 17, 240-250. [CrossRef]

8. Liu, P.; Mu, D. Evaluating sustainability of truck weight regulations: A system dynamics view. J. Ind. Eng. Manag. 2015, 8, 1711-1730. [CrossRef]

9. Tsamboulas, D.; Vrenken, H.; Lekka, A.M. Assessment of a transport policy potential for intermodal mode shift on a European scale. Transp. Res. Part A Policy Pract. 2007, 41, 715-733. [CrossRef]

10. Woodburn, A.; Browne, M.; Piotrowska, M.; Allen, J. Literature Review WM7: Scope for Modal Shift through Fiscal, Regulatory and Organisational Change. Available online: http:/ /www.greenlogistics.org/SiteResources/e03d3ccc-eabe-4a86-b575-ef0e5d465343_WM7\%20\%20Westminster\%20-\%20Modal\%20Shift.pdf (accessed on 10 July 2015).

11. Park, M.; Regan, A.; Yang, C.H. Emissions impacts of a modal shift: A case study of the Southern California ports region. J. Int. Logist. Trade 2007, 5, 67-81.

12. Johnston, M.; Bickford, E.; Holloway, T.; Dresser, C.; Adams, T.M. Impacts of biodiesel blending on freight emissions in the Midwestern United States. Transp. Res. Part D Transp. Environ. 2012, 17, 457-465. [CrossRef]

13. Bickford, E.; Holloway, T.; Karambelas, A.; Johnston, M.; Adams, T.; Janssen, M.; Moberg, C. Emissions and air quality impacts of truck-to-rail freight modal shifts in the Midwestern United States. Environ. Sci. Technol. 2013, 48, 446-454. [CrossRef] [PubMed]

14. Regmi, M.B.; Hanaoka, S. Assessment of modal shift and emissions along a freight transport corridor between Laos and Thailand. Int. J. Sustain. Transp. 2015, 9, 192-202. [CrossRef]

15. Awasthi, A.; Chauhan, S.S.; Omrani, H. Application of fuzzy TOPSIS in evaluating sustainable transportation systems. Expert. Syst. Appl. 2011, 38, 12270-12280. [CrossRef]

16. Vermote, L.; Macharis, C.; Putman, K. A road network for freight transport in Flanders: Multi-actor multi-criteria assessment of alternative ring ways. Sustainability 2013, 5, 4222-4246. [CrossRef]

17. Tang, X.; Zhang, J.; Xu, P. A multi-objective optimization model for sustainable logistics facility location. Transp. Res. Part D Transp. Environ. 2013, 22, 45-48.

18. Hajibabai, L.; Bai, Y.; Ouyang, Y. Joint optimization of freight facility location and pavement infrastructure rehabilitation under network traffic equilibrium. Transp. Res. Part B Meth. 2014, 63, 38-52. [CrossRef]

19. Qu, Y.; Bektaş, T.; Bennell, J. Sustainability SI: Multimode multicommodity network design model for intermodal freight transportation with transfer and emission costs. Netw. Spat. Econ. 2016, 16, 303-329. [CrossRef]

20. Anand, N.; van Duin, R.; Tavasszy, L. Ontology-based multi-agent system for urban freight transportation. Int. J. Urban Sci. 2014, 18, 133-153. [CrossRef]

21. Van Lier, T.; Caris, A.; Macharis, C. Sustainability SI: Bundling of outbound freight flows: Analyzing the potential of internal horizontal collaboration to improve sustainability. Netw. Spat. Econ. 2016, 16, 277-302. [CrossRef]

22. Aditjandra, P.T.; Galatioto, F.; Bell, M.C.; Zunder, T.H. Evaluating the impacts of urban freight traffic: Application of micro-simulation at a large establishment. Eur. J. Transp. Infrastruct. Res. 2016, 16, 4-22.

23. Schade, W.; Rothengatter, W. Strategic sustainability analysis: Broadening existing assessment approaches for transport policies. Transp. Res. Rec. 2001, 1756, 3-11. [CrossRef]

24. De Jong, G.; Gunn, H.; Walker, W. National and international freight transport models: An overview and ideas for future development. Transp. Rev. 2004, 24, 103-124. [CrossRef]

25. Homer, J.B.; Keane, T.E.; Lukiantseva, N.O. Evaluating Strategies to Improve Railroad Performance-A System Dynamics Approach. Available online: http://www.norbridgeinc.com/industries/WSC172.pdf (accessed on 12 October 2015).

26. Ülengin, F.; Kabak, Ö.; Önsel, Ş.; Ülengin, B.; Aktaş, E. A Problem-structuring model for analyzing transportation-environment relationships. Eur. J. Oper. Res. 2010, 200, 844-859. [CrossRef]

27. Richardson, B.C. Sustainable transport: Analysis frameworks. J. Transp. Geogr. 2005, 13, 29-39. [CrossRef] 
28. Maheshwari, P.; Khaddar, R.; Kachroo, P.; Paz, A. Dynamic modeling of performance indices for planning of sustainable transportation systems. Netw. Spat. Econ. 2016, 16, 371-393. [CrossRef]

29. Shepherd, S.P. A review of system dynamics models applied in transportation. Transp. B Transp. Dynam. 2014, 2, 83-105. [CrossRef]

30. Abbas, K.A.; Bell, M.G. System dynamics applicability to transportation modeling. Transp. Res. Part A Policy Pract. 1994, 28, 373-390. [CrossRef]

31. Han, J.; Hayashi, Y. A system dynamics model of $\mathrm{CO}_{2}$ mitigation in China's inter-city passenger transport. Transp. Res. Part D Transp. Environ. 2008, 13, 298-305. [CrossRef]

32. Ercan, T.; Onat, N.C.; Tatari, O. Investigating carbon footprint reduction potential of public transportation in United States: A system dynamics approach. J. Clean. Prod. 2016, 133, 1260-1276. [CrossRef]

33. Fiorello, D.; Fermi, F.; Bielanska, D. The ASTRA model for strategic assessment of transport policies. Syst. Dynam. Rev. 2010, 26, 283-290. [CrossRef]

34. Haghani, A.; Lee, S.Y.; Byun, J.H. A system dynamics approach to land use/transportation system performance modeling part I: Methodology. J. Adv. Transp. 2003, 37, 1-41. [CrossRef]

35. Fallah-Fini, S.; Rahmandad, H.; Triantis, K.; de la Garza, J.M. Optimizing highway maintenance operations: Dynamic considerations. Syst. Dynam. Rev. 2010, 26, 216-238. [CrossRef]

36. Goh, Y.M.; Love, P.E. Methodological application of system dynamics for evaluating traffic safety policy. Saf. Sci. 2012, 50, 1594-1605. [CrossRef]

37. Liu, S.; Triantis, K.P.; Sarangi, S. A framework for evaluating the dynamic impacts of a congestion pricing policy for a transportation socioeconomic system. Transp. Res. Part A Policy Pract. 2010, 44, 596-608. [CrossRef]

38. Cao, J.; Menendez, M. System dynamics of urban traffic based on its parking-related-states. Transp. Res. Part B Meth. 2015, 81, 718-736. [CrossRef]

39. China Railway Corporation. Code for Design of Railway Line (GB 50090-2006); China Planning Press: Beijing, China, 2006. (In Chinese)

40. Hao, H.; Wang, H.W.; Ouyang, M.G.; Cheng, F. Vehicle survival patterns in China. Sci. China Technol. Sci. 2011, 54, 625-629. [CrossRef]

41. Ministry of Transport of China. Specifications for Design of Highway Asphalt Pavement (JTG D20-2006); China Communications Press: Beijing, China, 2006. (In Chinese)

42. Sun, L.; Liu, X. General deterioration equation for pavement performance. J. Tongji Univ. 1995, 23, 512-518. (In Chinese)

43. Saha, P.; Sarkar, A.K.; Pal, M. Evaluation of speed-flow characteristics on two-lane highways with mixed traffic. Transport 2015. [CrossRef]

44. Krause, A.; Musingwini, C. Modelling open pit shovel-truck systems using the Machine Repair Model. J. S. Afr. Inst. Min. Metall. 2007, 107, 469-476.

45. Fiorello, D.; Martino, A.; Rinaldi, M. The ASTRA-Italia Model for Strategic Assessment of Transport Policies and Investments. Available online: http://www.systemdynamics.org/conferences/2002/proceed/papers/ Fiorell1.pdf (accessed on 6 December 2014).

46. Hang, W.; Li, X.; He, J. Research of highway freight vehicle operating cost based on vehicle axle type classification. J. Highw. Transp. Res. Dev. 2005, 22, 170-174. (In Chinese)

47. Maurer, H.H. Development of an Integrated Model for Estimating Emissions from Freight Transport. Available online: http://www.its.leeds.ac.uk/peat/images/uploads/1257162332MAURER\%20PhD\% 20thesis.pdf (accessed on 20 October 2015).

48. Niu, J. Prediction of demand for iron ores in China based on principal component regression analysis. J. Univ. Sci. Technol. Beijing 2011, 33, 1178-1181. (In Chinese)

49. Jia, L.; Xu, D. Analysis and prediction of the demand for iron ore: Using panel, grey, co-integration and ARIMA models. Resour. Sci. 2014, 36, 1382-1391. (In Chinese)

(C) 2017 by the authors. Licensee MDPI, Basel, Switzerland. This article is an open access article distributed under the terms and conditions of the Creative Commons Attribution (CC BY) license (http:/ / creativecommons.org/licenses/by/4.0/). 